OPEN ACCESS

Edited by:

Massimo Gadina,

National Institute of Arthritis

and Musculoskeletal and

Skin Diseases,

United States

Reviewed by:

Carmen Clapp,

National Autonomous University

of Mexico, Mexico

Jean-Eric Ghia,

University of Manitoba, Canada

Luis R. Espinoza,

LSU Health Sciences Center

New Orleans, United States

*Correspondence:

Paul P. Tak

p.p.tak@amc.uva.n

Specialty section:

This article was submitted

to Inflammation,

a section of the journal

Frontiers in Immunology

Received: 23 March 2017

Accepted: 06 June 2017

Published: 23 June 2017

Citation:

Tang MW, Garcia S, Gerlag DM,

Tak PP and Reedquist KA (2017)

Insight into the Endocrine System and the Immune System: A Review

of the Inflammatory Role of

Prolactin in Rheumatoid Arthritis

and Psoriatic Arthritis.

Front. Immunol. 8:720.

doi: 10.3389/fimmu.2017.00720

\section{Insight into the Endocrine System and the Immune System: A Review of the Inflammatory Role of Prolactin in Rheumatoid Arthritis and Psoriatic Arthritis}

\author{
Man W. Tang ${ }^{1,2}$, Samuel Garcia ${ }^{3}$, Danielle M. Gerlag ${ }^{1,4}$, Paul P. Tak $^{1,5,6,7 *}$ and \\ Kris A. Reedquist ${ }^{3}$
}

${ }^{1}$ Department of Clinical Immunology and Rheumatology, Amsterdam Rheumatology and Immunology Centre, Academic Medical Centre/University of Amsterdam, Amsterdam, Netherlands, ' 2 Department of Experimental Immunology, Academic Medical Centre/University of Amsterdam, Amsterdam, Netherlands, ${ }^{3}$ Laboratory of Translational Immunology, Department of Rheumatology and Clinical Immunology, University Medical Center, Utrecht, Netherlands, ${ }^{4} \mathrm{GlaxoSmithKline,} \mathrm{Cambridge,}$ United Kingdom, ${ }^{5}$ GlaxoSmithKline, Stevenage, United Kingdom, ${ }^{6}$ Ghent University, Ghent, Belgium, ${ }^{7}$ University of Cambridge, Cambridge, United Kingdom

Rheumatoid arthritis (RA) is a chronic autoimmune disease that affects females three times more frequently than males. A potential role for hormones, such as prolactin (PRL), may in part explain this phenomenon. The risk of developing $R A$ is increased in women who are lactating after the first pregnancy, which might be related to breastfeeding and the release of PRL. Other studies found a protective effect of PRL on RA development. Some studies have reported that hyperprolactinemia is more common in RA and serum PRL levels are correlated with several disease parameters, although others could not confirm these findings. Overall the plasma $P R L$ levels are on average not elevated in RA. Previously, a small number of open-label clinical trials using bromocriptine, which indirectly decreases PRL levels, were performed in RA patients and showed clinical benefit, although others found the opposite effect. Locally produced PRL at the site of inflammation may have a crucial role in $R A$ as well, as it has been shown that $P R L$ can be produced by synovial macrophages. Locally produced PRL has both pro-inflammatory and anti-inflammatory effects in arthritis. Psoriatic arthritis (PSA) is also an autoinflammatory disease, in which the prolactin receptor is also expressed in macrophages. The aim of this review is to provide an overview of the potential role of $P R L$ signaling in inflammatory joint diseases (RA and PsA) and its potential as a therapeutic target.

\section{Keywords: rheumatoid arthritis, synovium, signaling and activation, clinical trials and methods, cytokines and} inflammatory mediators, hormones, inflammation, macrophages

\section{KEY MESSAGES}

- Prolactin (PRL) can be locally produced by macrophages, but also T cells and synovial fibroblasts.

- The prolactin receptor (PRLR) is expressed in synovial macrophages, lymphocytes, and fibroblasts.

- PRL interaction with its receptor can enhance or inhibit pro-inflammatory cytokine production in a cell-specific manner. 
- The balance of pro- and anti-inflammatory effects of PRL, as well as potential differences in the contributions of systemic and locally produced PRL, will need to be addressed in considering PRLR antagonists as a new strategy in the treatment of inflammatory arthritis.

\section{RHEUMATOID ARTHRITIS}

Rheumatoid arthritis (RA) is a chronic autoimmune disease, which is characterized by pain, swelling, and stiffness of the joints due to synovial inflammation that if untreated leads to progressive and irreversible destruction of cartilage and bone. The inflammatory process in the synovium is the hallmark of the disease (1). RA is one of the most common autoimmune diseases, affecting approximately $1 \%$ of the population worldwide, and females three times more frequently than males. It is associated with an increased incidence of cardiovascular morbidity and mortality (2). Due to the heterogeneity of the disease, not only seen in the clinic but also at the molecular level, it is difficult to diagnose patients based on one single diagnostic test. Therefore, RA patients have been classified for many years according to the 1987 American College of Rheumatology (ACR) criteria for RA (3). More recently, new classification criteria were developed by the ACR and the European League Against Rheumatism (EULAR), resulting in the 2010 ACR/EULAR criteria for RA $(4,5)$. An important difference with the 1987 ACR criteria is the use of the presence of anti-citrullinated protein antibodies, which are highly specific for RA. The presence of these autoantibodies together with IgM rheumatoid factor can be detected in the serum of $70-80 \%$ of patients and can precede the onset of clinical signs and symptoms for many years $(6,7)$. Their presence is associated with a more severe and destructive disease phenotype. Patients with RA can be treated with (a combination of) non-steroidal anti-inflammatory drugs, corticosteroids, disease-modifying antirheumatic drugs, and/or biological targeted therapies, such as tumor necrosis factor (TNF) inhibitors, B-cell depleting therapy, CTLA4-Ig treatment, and interleukin-6 (IL-6) receptor antibody treatment $(8,9)$. However, not all patients with RA respond to the available array of antirheumatic drugs. Therefore, identifying new therapeutic targets and developing effective treatment strategies remains highly important.

\section{ENDOCRINE HORMONES IN RA}

Several hormones are known to be involved or associated with inflammatory joint diseases such as RA, suggesting crosstalk between the endocrine hormones and immunity as recently highlighted (10). In addition, cortisol is known as the strongest endogenous anti-inflammatory hormone (11). RA patients have elevated cortisol levels but inadequately low in relation to ongoing inflammation, which explains the efficacy of corticosteroids in the treatment of RA.

As RA predominantly affects women, sex hormones such as prolactin (PRL) and estrogen (estradiol) have long been thought to play an important role in RA pathogenesis (12-15). Recent evidence suggests that estrogens can have both pro- and anti-inflammatory activities (16), and similar pro- and anti-inflammatory effects of PRL in RA have been recently reviewed $(14,15)$. For decades it has been acknowledged that in about $65 \%$ of the RA patients, disease activity diminishes during pregnancy. This may be explained by a period of transient relative hypercortisolism. A few animal studies have also suggested the beneficial effect of higher PRL levels during (the last trimester) of pregnancy in suppressing the immune responses required for successful maternal-fetal interaction $(17,18)$. This was also confirmed by a recent study in adjuvant-induced arthritis in which it showed hyperprolactinemia and treatment with dopamine antagonists reducing joint inflammation and pro-inflammatory cytokine production (19). Recently, it has been shown that PRL treatment and lack of PRL receptor (PRLR) signaling downregulates and upregulates, respectively, joint inflammation, osteoclastogenesis, and the expression of pro-inflammatory cytokines related to Th17 and regulatory $\mathrm{T}$ cells (20).

After giving birth, a reactivation of disease activity is often seen, which might be influenced by the release of PRL in the context of breastfeeding (21). The risk of developing RA is increased in women who are lactating after the first pregnancy $(22,23)$, although others found a protective effect on RA development $(24,25)$. Nowadays it is still unclear whether PRL-PRLR interaction leads to pro- or anti-inflammatory effects in RA. The discrepancies might be explained by serum PRL levels, which are measured in relatively small patients groups and targeting only (complex) systemic secreted pulsatile hormone by bromocriptine. In the last two decades, increasing evidence has shown interactions of PRL with the immune system (26-29). Homeostasis during inflammation is achieved by a balance between cytokines and endocrine hormones. Among the protein hormones, it has been most clearly documented for PRL, playing an important role in communication and regulation of the cells of the immune system (10). Here, we will summarize the known aspects of the role of PRL in RA and also proriatic arthritis (PsA).

\section{THE ROLE OF PRL IN RA AND PsA}

PRL is a neuroendocrine hormone, which is mainly secreted by the anterior pituitary gland. PRL has pleiotropic functions, ranging from inducing lactation to influences on reproductive functions, calcium metabolism, and also immune reactivity (30). PRL can also be produced by cells in many extrapituitary sites (31). It has been shown that PRL can be produced by macrophages, B-cells, NK cells, T-cells, thymocytes, and peripheral blood mononuclear cells (32-35). Macrophages play a crucial role in RA as well. The relationship between PRL and RA was also suggested due to the human PRL gene, which is located on chromosome 6 close to the HLA region (36), which on its own is associated with RA. Another study has found a linkage disequilibrium between the PRL gene and major histocompatibility complex genes, known to be associated with RA (37). It has also been shown that the PRL1149 G/T polymorphism associated significantly in Caucasian patients with RA (38).

Previous studies have shown elevated levels of PRL in RA patients compared to controls, both in females and in males (39-41), although these findings have not been confirmed in all studies $(13,42)$. The contradictory results can at least be 
partially understood by the small sample size of the studies. It is also not always clear whether fasting morning samples were obtained for the measurement of PRL. Elevated levels of PRL might be explained by enhanced systemic secretion or increased PRL production by immune cells, such as macrophages, which would suggest a correlation between PRL levels and disease activity. Studies exploring this correlative effect have produced contradicting results however. Our group has shown that in a cohort of 119 active RA patients, the percentage of patients with hyperprolactinemia was comparable to the reported incidence in the general population, and plasma PRL levels did not correlate with any of the parameters reflecting disease activity (43). Similar results were found in an independent cohort of 30 active RA patients (43). In another, independent patient group we have confirmed similar plasma PRL levels in 22 active RA patients compared to 16 healthy controls (44). In contrast, higher PRL levels have been reported in patients with psoriasis compared to control disease and healthy controls (45), and it has been suggested that PRL may play a role in the pathogenesis of psoriasis (46). Collectively, most of the evidence suggests that plasma PRL levels are on average not elevated in RA, while more validation is needed in conditions like psoriasis.

PRL levels in plasma and synovial fluid (SF) of patients with RA and osteoarthritis (OA) have been reported to be comparable, but the potential relationship between PRL levels in blood and SF has only recently been studied $(47,48)$. Previously, PRL was found in SF (49). We observed comparable levels of PRL in the plasma and SF of RA patients and possibly lower PRL levels in the SF compared to the plasma level in PsA. PRL is locally expressed in the synovial tissue of RA and PsA patients (50). PRL mRNA expression in the synovial tissue of RA and PsA patients positively correlates with several clinical disease parameters, including erythrocyte sedimentation rate, swollen joint count of 28 joints, visual analog scale of global disease activity, and disease activity score of 28 joints (50). This finding of locally expressed PRL in synovial tissue provides direct evidence that endocrine hormones could affect the immune system in RA and PsA. Taken together, the presence of the PRL protein in the SF and the expression of PRL in synovial tissue suggest the local production of PRL by immune cells in RA and PsA. Previously, it has been shown that lymphocytes from RA synovial tissue might synthesize PRL (51). Interestingly, monocyte-derived macrophages from RA patients can produce PRL. To have a better understanding of the type of polarization in the different diseases, and the production of PRL by those macrophages, we used monocyte-derived macrophages from healthy donors and differentiated them in RA, PsA, spondyloarthritis, and gout SF. Common macrophage agonists present in SF include CD40L, IgG complexes, TNF, and lipopolysaccharide (LPS), but we found that these stimuli failed to further modulate PRL expression in RA and PsA SF-differentiated macrophages (50). Although the component of SF responsible for stimulating macrophage PRL production remains unknown, the regulation of local PRL production by macrophages provides further evidence of the important crosstalk between the immune and endocrine systems in the inflamed compartment. Together, these data suggest that systemically secreted PRL (by the pituitary) may have a limited role in RA, except perhaps during phases of marked hyperprolactemia during breast feeding. The available data also raise the possibility that local production of PRL by immune cells (acting via the autocrine/paracrine loop) may be important $(52,53)$.

\section{PRL RECEPTOR IN RA AND PsA}

The PRLR belongs to the hematopoietin receptor superfamily and is present in atherosclerotic plaques at the sites of most prominent inflammation where it is mainly expressed by macrophages (54). Binding of PRL to its receptor activates several signaling pathways, especially the Janus kinase-signal transducer and activator of transcription pathway (55). PRL induces production of different cytokines in murine peritoneal macrophages, including interleukin- $1 \beta$ (IL-1 $\beta$ ), interleukin-12 $\beta$ (IL-12 $\beta$ ), interferon- $\gamma$ (IFN- $\gamma$ ), and TNF (56). It has also been confirmed by others that PRL induces release of IL-12 in synergy with IFN- $\gamma$ by murine peritoneal macrophages (57). Recently, it has been shown that PRL increases TNF expression in peripheral monocytes of RA patients (58). It was also reported that PRL, in the presence of LPS, enhanced the release of heme oxygenase- 1 and vascular endothelial growth factor by human monocytes and macrophages (59). In the context of arthritis, we have shown that the PRLR is present, mainly on macrophages, but also on von Willebrand's factor-positive endothelial cells, in the synovial tissue of RA and PsA patients (43). The expression of the PRLR is significantly higher in the synovial tissue of RA and PsA patients compared to OA, a finding confirmed independently measuring synovial mRNA expression (43).

The presence of immunomodulatory cytokines and other factors in tissue can impact on gene expression and subsequent macrophage functional responses, a process referred to as polarization; it has previously been shown that synovial tissue macrophages in inflammatory arthritis resemble polarized macrophages (60). In monocyte-derived macrophages, which were differentiated using different stimuli, we observed the highest PRLR expression in IFN- $\gamma$ and IL-10-polarized macrophages. Consistent with previous literature, our data showed that PRL enhances the expression of several genes encoding for pro-inflammatory cytokines (IL-6, IL-8, IL-12 $\beta$, TNF) and chemokines (i.e., CXCL3, 5, 6, and 11). Additionally, PRL enhances the production of IL-6, IL-8, and IL- $12 \beta$ by macrophages (43). This effect on pro-inflammatory cytokine production was also seen in RA synovial tissue explants stimulated with PRL, but not in joints and synovial fibroblasts of rodents with inflammatory arthritis, where PRL treatment and lack of PRL signaling inhibited and stimulated, respectively, pro-inflammatory cytokine production $(19,20)$.

\section{PRL(R) ANTAGONISTS AS TREATMENT FOR RA AND PsA?}

The concept of engagement of PRL with its receptor in synovial tissue (i.e., auto-/paracrine) identifies a potential target for therapeutic intervention. This notion is supported by experimental data. In animal models bromocriptine, a dopamine agonist which indirectly reduces PRL levels, suppresses postpartum 
exacerbation of collagen-induced arthritis (61). Another study reported exacerbation of collagen-induced arthritis by bromocriptine (62). Also, systemically administered bromocriptine has been shown to improve signs and symptoms of RA patients $(63,64)$, although others could not confirm this finding (65). Similarly, a case report described amelioration of severe RA after treatment for coincidental hyperprolactinemia with cabergoline, a dopamine receptor agonist (66). Recently, it has been shown that regardless of the serum PRL levels in patients with PsA, administration of bromocriptine improves joint and skin symptoms as well (67). While these studies are interesting and hypothesis-generating, they need to be confirmed in controlled design studies.

An autocrine loop of PRL signaling may enhance the inflammatory response of activated monocytes (68). According to previous studies and data discussed above, the concept of locally produced PRL, which can activate its receptor on target cells, has emerged as a new mechanism not only in RA but also in other pathological contexts, including breast and prostate cancer (69-71). Dopamine is inappropriate for downregulating PRL production in extrapituitary tissues, therefore alternative therapeutic approaches have been developed to block PRLR-mediated signaling in stead of PRL production per se in target cells. It has been shown that PRL variants acting as competitive PRLR antagonists can efficiently downregulate PRLR signaling, cell survival, and/ or proliferation in various breast or prostate cancer preclinical assays $(70,71)$. Although a phase I clinical trial with PRLR neutralizing antibodies (LFA102) in breast or prostate cancer patients showed no antitumor activity when used as monotherapy (72), the cumulative studies reviewed here support the rationale to test this approach in chronic inflammatory diseases. Further studies

\section{REFERENCES}

1. Tak PP, Bresnihan B. The pathogenesis and prevention of joint damage in rheumatoid arthritis: advances from synovial biopsy and tissue analysis. Arthritis Rheum (2000) 43(12):2619-33. doi:10.1002/1529-0131(200012)43: $12<2619::$ AID-ANR1 $>3.0$. CO 2 - $\mathrm{V}$

2. Gkaliagkousi E, Gavriilaki E, Doumas M, Petidis K, Aslanidis S, Stella D. Cardiovascular risk in rheumatoid arthritis: pathogenesis, diagnosis, and management. JClin Rheumatol (2012) 18(8):422-30. doi:10.1097/RHU. ob013e31827846b1

3. Arnett FC, Edworthy SM, Bloch DA, McShane DJ, Fries JF, Cooper NS, et al. The American Rheumatism Association 1987 revised criteria for the classification of rheumatoid arthritis. Arthritis Rheum (1988) 31(3):315-24. doi:10.1002/art.1780310302

4. Aletaha D, Neogi T, Silman AJ, Funovits J, Felson DT, Bingham CO 3rd, et al. 2010 Rheumatoid arthritis classification criteria: an American College of Rheumatology/European League Against Rheumatism collaborative initiative. Arthritis Rheum (2010) 62(9):2569-81. doi:10.1002/art.27584

5. Neogi T, Aletaha D, Silman AJ, Naden RL, Felson DT, Aggarwal R, et al. The 2010 American College of Rheumatology/European League Against Rheumatism classification criteria for rheumatoid arthritis: phase 2 methodological report. Arthritis Rheum (2010) 62(9):2582-91. doi:10.1002/art.27580

6. Schellekens GA, Visser H, de Jong BA, van den Hoogen FH, Hazes JM, Breedveld FC, et al. The diagnostic properties of rheumatoid arthritis antibodies recognizing a cyclic citrullinated peptide. Arthritis Rheum (2000) 43(1): 155-63. doi:10.1002/1529-0131(200001)43:1<155::AID-ANR20>3.0.CO;2-3

7. Rantapää-Dahlqvist S, de Jong BA, Berglin E, Hallmans G, Wadell G, Stenlund $\mathrm{H}$, et al. Antibodies against cyclic citrullinated peptide and IgA are needed to explore the potential of PRLR antagonists as a novel therapeutic approach in conditions like RA and PsA.

\section{CONCLUSION}

The current literature is not conclusive as to whether PRL had a broad pro-inflammatory or anti-inflammatory effect in RA, rather suggesting cell-specific responses to this hormone. Systemic secreted PRL and locally produced PRL may make distinct contributions to inflammatory arthritis as systemic levels do not correlate with disease activity parameters. PRL is present in the RA $\mathrm{SF}$ and can be produced by macrophages and also other immune cells. The PRLR is expressed in macrophages, as well as T cells, and upon activation of the PRLR by PRL, pro-inflammatory cytokine production is induced in both macrophages and $\mathrm{T}$ cells. Therefore, targeting the PRLR would be an interesting novel approach in the treatment of inflammatory arthritis.

\section{AUTHOR CONTRIBUTIONS}

MT contributed to study conception and design, acquisition of the data, and analysis and interpretation of the data. SG contributed to study conception and design, contributed to acquisition of the data, and analysis and interpretation of the data. DG contributed to study conception and design, and analysis and interpretation of the data. PT contributed to study conception and design, and analysis and interpretation of the data. KR contributed to study conception and design, and analysis and interpretation of the data. All authors were involved in drafting the article or revising it critically for important intellectual content, and all authors approved the final version to be published.

rheumatoid factor predict the development of rheumatoid arthritis. Arthritis Rheum (2003) 48(10):2741-9. doi:10.1002/art.11223

8. Smolen JS, Aletaha D, Koeller M, Weisman MH, Emery P. New therapies for treatment of rheumatoid arthritis. Lancet (2007) 370(9602):1861-74. doi:10.1016/S0140-6736(07)60784-3

9. Tak PP, Kalden JR. Advances in rheumatology: new targeted therapeutics. Arthritis Res Ther (2011) 13(Suppl 1):S5. doi:10.1186/1478-6354-13-S1-S5

10. Kelley KW, Weigent DA, Kooijman R. Protein hormones and immunity. Brain Behav Immun (2007) 21(4):384-92. doi:10.1016/j.bbi.2006.11.010

11. Straub RH, Paimela L, Peltomaa R, Scholmerich J, Leirisalo-Repo M. Inadequately low serum levels of steroid hormones in relation to interleukin-6 and tumor necrosis factor in untreated patients with early rheumatoid arthritis and reactive arthritis. Arthritis Rheum (2002) 46(3):654-62. doi:10.1002/ art.10177

12. McMurray RW. Estrogen, prolactin, and autoimmunity: actions and interactions. Int Immunopharmacol (2001) 1(6):995-1008. doi:10.1016/ S1567-5769(01)00045-5

13. Orbach H, Zandman-Goddard G, Amital H, Barak V, Szekanecz Z, Szucs G, et al. Novel biomarkers in autoimmune diseases: prolactin, ferritin, vitamin $D$, and TPA levels in autoimmune diseases. Ann N Y Acad Sci (2007) 1109: 385-400. doi:10.1196/annals.1398.044

14. Clapp C, Adan N, Ledesma-Colunga MG, Solis-Gutierrez M, Triebel J, Martinez de la Escalera G. The role of the prolactin/vasoinhibin axis in rheumatoid arthritis: an integrative overview. Cell Mol Life Sci (2016) 73(15):2929-48. doi:10.1007/s00018-016-2187-0

15. Costanza M, Binart N, Steinman L, Pedotti R. Prolactin: a versatile regulator of inflammation and autoimmune pathology. Autoimmun Rev (2015) 14(3):223-30. doi:10.1016/j.autrev.2014.11.005 
16. Gordon D, Beastall GH, Thomson JA, Sturrock RD. Androgenic status and sexual function in males with rheumatoid arthritis and ankylosing spondylitis. Q J Med (1986) 60(231):671-9.

17. Lin J, Linzer DI. A novel megakaryocyte differentiation factor from mouse placenta. Trends Cardiovasc Med (1999) 9(6):167-71. doi:10.1016/ S1050-1738(99)00026-2

18. Müller H, Liu B, Croy BA, Head JR, Hunt JS, Dai G, et al. Uterine natural killer cells are targets for a trophoblast cell-specific cytokine, prolactin-like protein A. Endocrinology (1999) 140(6):2711-20. doi:10.1210/endo.140.6.6828

19. Adán N, Guzmán-Morales J, Ledesma-Colunga MG, Perales-Canales SI, Quintanar-Stéphano A, López-Barrera F, et al. Prolactin promotes cartilage survival and attenuates inflammation in inflammatory arthritis. J Clin Invest (2013) 123(9):3902-13. doi:10.1172/JCI69485

20. Ledesma-Colunga MG, Adan N, Ortiz G, Solís-Gutiérrez M, López-Barrera F, Martínez de la Escalera G, et al. Prolactin blocks the expression of receptor activator of nuclear factor kappaB ligand and reduces osteoclastogenesis and bone loss in murine inflammatory arthritis. Arthritis Res Ther (2017) 19(1):93. doi:10.1186/s13075-017-1290-4

21. Barrett JH, Brennan P, Fiddler M, Silman A. Breast-feeding and postpartum relapse in women with rheumatoid and inflammatory arthritis. Arthritis Rheum (2000) 43(5):1010-5. doi:10.1002/1529-0131(200005)43:5<1010::AIDANR8 $>3.0 . \mathrm{CO} ; 2-\mathrm{O}$

22. Silman A, Kay A, Brennan P. Timing of pregnancy in relation to the onset of rheumatoid arthritis. Arthritis Rheum (1992) 35(2):152-5. doi:10.1002/ art.1780350205

23. Brennan P, Silman A. Breast-feeding and the onset of rheumatoid arthritis. Arthritis Rheum (1994) 37(6):808-13. doi:10.1002/art.1780370605

24. Brun JG, Nilssen S, Kvale G. Breast feeding, other reproductive factors and rheumatoid arthritis. A prospective study. BrJ Rheumatol (1995) 34(6):542-6. doi:10.1093/rheumatology/34.6.542

25. Pikwer M, Bergstrom U, Nilsson JA, Jacobsson L, Berglund G, Turesson C. Breast feeding, but not use of oral contraceptives, is associated with a reduced risk of rheumatoid arthritis. Ann Rheum Dis (2009) 68(4):526-30. doi:10.1136/ $\operatorname{ard} .2007 .084707$

26. Chikanza IC, Petrou P, Chrousos G, Kingsley G, Panayi GS. Excessive and dysregulated secretion of prolactin in rheumatoid arthritis: immunopathogenetic and therapeutic implications. Br J Rheumatol (1993) 32(6):445-8. doi:10.1093/rheumatology/32.6.445

27. Chikanza IC, Petrou P, Kingsley G, Chrousos G, Panayi GS. Defective hypothalamic response to immune and inflammatory stimuli in patients with rheumatoid arthritis. Arthritis Rheum (1992) 35(11):1281-8. doi:10.1002/ art. 1780351107

28. Templ E, Koeller M, Riedl M, Wagner O, Graninger W, Luger A. Anterior pituitary function in patients with newly diagnosed rheumatoid arthritis. Br J Rheumatol (1996) 35(4):350-6. doi:10.1093/rheumatology/35.4.350

29. Zoli A, Lizzio MM, Ferlisi EM, Massafra V, Mirone L, Barini A, et al. ACTH, cortisol and prolactin in active rheumatoid arthritis. Clin Rheumatol (2002) 21(4):289-93. doi:10.1007/s100670200076

30. Neidhart M, Gay RE, Gay S. Prolactin and prolactin-like polypeptides in rheumatoid arthritis. Biomed Pharmacother (1999) 53(5-6):218-22. doi:10.1016/ S0753-3322(99)80091-2

31. Jara LJ, Lavalle C, Fraga A, Gómez-Sanchez C, Silveira LH, Martínez-Osuna P, et al. Prolactin, immunoregulation, and autoimmune diseases. Semin Arthritis Rheum (1991) 20(5):273-84. doi:10.1016/0049-0172(91)90028-X

32. Gingras MC, Margolin JF. Differential expression of multiple unexpected genes during U937 cell and macrophage differentiation detected by suppressive subtractive hybridization. Exp Hematol (2000) 28(1):65-76. doi:10.1016/ S0301-472X(00)00149-1

33. Matera L, Cutufia M, Geuna M, Contarini M, Buttiglieri S, Galin S, et al. Prolactin is an autocrine growth factor for the Jurkat human T-leukemic cell line. J Neuroimmunol (1997) 79(1):12-21. doi:10.1016/ S0165-5728(97)00096-9

34. O'Neal KD, Montgomery DW, Truong TM, Yu-Lee LY. Prolactin gene expression in human thymocytes. Mol Cell Endocrinol (1992) 87(1-3):R19-23. doi:10.1016/0303-7207(92)90251-Z

35. Pellegrini I, Lebrun JJ, Ali S, Kelly PA. Expression of prolactin and its receptor in human lymphoid cells. Mol Endocrinol (1992) 6(7):1023-31. doi:10.1210/ me.6.7.1023
36. Vera-Lastra O, Jara LJ, Espinoza LR. Prolactin and autoimmunity. Autoimmun Rev (2002) 1(6):360-4. doi:10.1016/S1568-9972(02)00081-2

37. Brennan P, Hajeer A, Ong KR, Worthington J, John S, Thomson W, et al. Allelic markers close to prolactin are associated with HLA-DRB1 susceptibility alleles among women with rheumatoid arthritis and systemic lupus erythematosus. Arthritis Rheum (1997) 40(8):1383-6. doi:10.1002/art.1780400804

38. Lee YH, Bae SC, Song GG. Meta-analysis of associations between functional prolactin - $1149 \mathrm{G} / \mathrm{T}$ polymorphism and susceptibility to rheumatoid arthritis and systemic lupus erythematosus. Clin Rheumatol (2015) 34(4):683-90. doi:10.1007/s10067-015-2904-3

39. Ram S, Blumberg D, Newton P, Anderson NR, Gama R. Raised serum prolactin in rheumatoid arthritis: genuine or laboratory artefact? Rheumatology (Oxford) (2004) 43(10):1272-4. doi:10.1093/rheumatology/keh307

40. Jorgensen C, Maziad H, Bologna C, Sany J. Kinetics of prolactin release in rheumatoid arthritis. Clin Exp Rheumatol (1995) 13(6):705-9.

41. Mateo L, Nolla JM, Bonnin MR, Navarro MA, Roig-Escofet D. High serum prolactin levels in men with rheumatoid arthritis. JRheumatol (1998) 25(11):2077-82.

42. Gutierrez MA, Garcia ME, Rodriguez JA, Mardonez G, Jacobelli S, Rivero S. Hypothalamic-pituitary-adrenal axis function in patients with active rheumatoid arthritis: a controlled study using insulin hypoglycemia stress test and prolactin stimulation. J Rheumatol (1999) 26(2):277-81.

43. Tang MW, Reedquist KA, Garcia S, Fernandez BM, Codullo V, VieiraSousa E, et al. The prolactin receptor is expressed in rheumatoid arthritis and psoriatic arthritis synovial tissue and contributes to macrophage activation. Rheumatology (Oxford) (2016) 55(12):2248-59. doi:10.1093/rheumatology/ kew316

44. Tang MW, Koopman FA, Visscher JP, de Hair MJ, Gerlag DM, Tak PP. Hormone, metabolic peptide, and nutrient levels in the earliest phases of rheumatoid arthritis-contribution of free fatty acids to an increased cardiovascular risk during very early disease. Clin Rheumatol (2017) 36(2):269-78. doi:10.1007/s10067-016-3456-x

45. Giasuddin AS, El-Sherif AI, El-Ojali SI. Prolactin: does it have a role in the pathogenesis of psoriasis? Dermatology (1998) 197(2):119-22. doi:10.1159/000017981

46. Shelly S, Boaz M, Orbach H. Prolactin and autoimmunity. Autoimmun Rev (2012) 11(6-7):A465-70. doi:10.1016/j.autrev.2011.11.009

47. Rovensky J, Kvetnansky R, Radikova Z, Imrich R, Greguska O, Vigas M, et al. Hormone concentrations in synovial fluid of patients with rheumatoid arthritis. Clin Exp Rheumatol (2005) 23(3):292-6.

48. Macho L, Rovensky J, Radikova Z, Imrich R, Greguska O, Vigas M. [Levels of hormones in plasma and in synovial fluid of knee joint of patients with rheumatoid arthritis]. Cas Lek Cesk (2007) 146(3):292-6.

49. Ogueta S, Munoz J, Obregon E, Delgado-Baeza E, Garcia-Ruiz JP. Prolactin is a component of the human synovial liquid and modulates the growth and chondrogenic differentiation of bone marrow-derived mesenchymal stem cells. Mol Cell Endocrinol (2002) 190(1-2):51-63. doi:10.1016/S0303-7207(02)00013-8

50. Tang MW, Reedquist KA, Garcia S, Gerlag DM, Tak PP. 1.57 Prolactin is locally produced in the synovium of patients with inflammatory arthritic diseases and promotes macrophage activation. Ann Rheum Dis (2014) 73(Suppl 1):A24-5. doi:10.1136/annrheumdis-2013-205124.56

51. Nagafuchi H, Suzuki N, Kaneko A, Asai T, Sakane T. Prolactin locally produced by synovium infiltrating $\mathrm{T}$ lymphocytes induces excessive synovial cell functions in patients with rheumatoid arthritis. JRheumatol (1999) 26(9):1890-900.

52. Clevenger CV, Plank TL. Prolactin as an autocrine/paracrine factor in breast tissue. J Mammary Gland Biol Neoplasia (1997) 2(1):59-68. doi:10.102 3/A:1026325630359

53. Ben-Jonathan N, Liby K, McFarland M, Zinger M. Prolactin as an autocrine/ paracrine growth factor in human cancer. Trends Endocrinol Metab (2002) 13(6):245-50.

54. Reuwer AQ, van Eijk M, Houttuijn-Bloemendaal FM, van der Loos CM, Claessen N, Teeling P, et al. The prolactin receptor is expressed in macrophages within human carotid atherosclerotic plaques: a role for prolactin in atherogenesis? J Endocrinol (2011) 208(2):107-17. doi:10.1677/JOE-10-0076

55. Ben-Jonathan N, LaPensee CR, LaPensee EW. What can we learn from rodents about prolactin in humans? Endocr Rev (2008) 29(1):1-41. doi:10.1210/ er.2007-0017 
56. Tripathi A, Sodhi A. Prolactin-induced production of cytokines in macrophages in vitro involves JAK/STAT and JNK MAPK pathways. Int Immunol (2008) 20(3):327-36. doi:10.1093/intimm/dxm145

57. Majumder B, Biswas R, Chattopadhyay U. Prolactin regulates antitumor immune response through induction of tumoricidal macrophages and release of IL-12. Int J Cancer (2002) 97(4):493-500. doi:10.1002/ijc.1624

58. Tang C, Li Y, Lin X, Ye J, Li W, He Z, et al. Prolactin increases tumor necrosis factor alpha expression in peripheral CD14 monocytes of patients with rheumatoid arthritis. Cell Immunol (2014) 290(1):164-8. doi:10.1016/j. cellimm.2014.06.005

59. Malaguarnera L, Imbesi R, Di Rosa M, Scuto A, Castrogiovanni P, Messina A, et al. Action of prolactin, IFN-gamma, TNF-alpha and LPS on heme oxygenase-1 expression and VEGF release in human monocytes/ macrophages. Int Immunopharmacol (2005) 5(9):1458-69. doi:10.1016/j. intimp.2005.04.002

60. Ambarus CA, Noordenbos T, de Hair MJ, Tak PP, Baeten DL. Intimal lining layer macrophages but not synovial sublining macrophages display an IL-10 polarized-like phenotype in chronic synovitis. Arthritis Res Ther (2012) 14(2):R74. doi:10.1186/ar3796

61. Whyte A, Williams RO. Bromocriptine suppresses postpartum exacerbation of collagen-induced arthritis. Arthritis Rheum (1988) 31(7):927-8. doi:10.1002/ art.1780310717

62. Mattsson R, Mattsson A, Hansson I, Holmdahl R, Rook GA, Whyte A. Increased levels of prolactin during, but not after, the immunisation with rat collagen II enhances the course of arthritis in DBA/1 mice. Autoimmunity (1992) 11(3):163-70. doi:10.3109/08916939209035151

63. Figueroa F, Carrion F, Martinez ME, Rivero S, Mamani I, Gonzalez G. [Effects of bromocriptine in patients with active rheumatoid arthritis]. Rev Med Chil (1998) 126(1):33-41.

64. Figueroa FE, Carrion F, Martinez ME, Rivero S, Mamani I. Bromocriptine induces immunological changes related to disease parameters in rheumatoid arthritis. Br JRheumatol (1997) 36(9):1022-3. doi:10.1093/ rheumatology/36.9.1022

65. Salesi M, Sadeghihaddadzavareh S, Nasri P, Namdarigharaghani N, Farajzadegan Z, Hajalikhani M. The role of bromocriptine in the treatment of patients with active rheumatoid arthritis. Int J Rheum Dis (2013) 16(6):662-6. doi:10.1111/1756-185x.12015
66. Erb N, Pace AV, Delamere JP, Kitas GD. Control of unremitting rheumatoid arthritis by the prolactin antagonist cabergoline. Rheumatology (Oxford) (2001) 40(2):237-9. doi:10.1093/rheumatology/40.2.237

67. Kokot I, Pawlik-Sobecka L, Placzkowska S, Piwowar A. Prolactin as an immunomodulatory factor in psoriatic arthritis. Postepy Hig Med Dosw (Online) (2013) 67(0):1265-72. doi:10.5604/17322693.1079893

68. López-Rincón G, Pereira-Suárez AL, Del Toro-Arreola S, SánchezHernández PE, Ochoa-Zarzosa A, Muñoz-Valle JF, et al. Lipopolysaccharide induces the expression of an autocrine prolactin loop enhancing inflammatory response in monocytes. J Inflamm (2013) 10(1):24. doi:10.1186/14769255-10-24

69. Clevenger CV, Zheng J, Jablonski EM, Galbaugh TL, Fang F. From bench to bedside: future potential for the translation of prolactin inhibitors as breast cancer therapeutics. J Mammary Gland Biol Neoplasia (2008) 13(1):147-56. doi:10.1007/s10911-008-9074-8

70. Goffin V, Bernichtein S, Touraine P, Kelly PA. Development and potential clinical uses of human prolactin receptor antagonists. Endocr Rev (2005) 26(3):400-22. doi:10.1210/er.2004-0016

71. Goffin V, Hoang DT, Bogorad RL, Nevalainen MT. Prolactin regulation of the prostate gland: a female player in a male game. Nat Rev Urol (2011) 8(11):597-607. doi:10.1038/nrurol.2011.143

72. Agarwal N, Machiels JP, Suárez C, Lewis N, Higgins M, Wisinski K, et al. Phase I study of the prolactin receptor antagonist LFA102 in metastatic breast and castration-resistant prostate cancer. Oncologist (2016) 21(5):535-6. doi:10.1634/theoncologist.2015-0502

Conflict of Interest Statement: DG and PT are currently employees of GSK, UK. GSK had no involvement in this project. Other authors do not have competing interests.

Copyright (c) 2017 Tang, Garcia, Gerlag, Tak and Reedquist. This is an open-access article distributed under the terms of the Creative Commons Attribution License (CC BY). The use, distribution or reproduction in other forums is permitted, provided the original author(s) or licensor are credited and that the original publication in this journal is cited, in accordance with accepted academic practice. No use, distribution or reproduction is permitted which does not comply with these terms. 